\title{
I 026 Infarct size determines infarct healing and ventricular remodeling in patients with successfully reperfused ST-elevation myocardial infarction
}

\author{
Pier Giorgio Masci*, Steven Dymarkowski, Stefan Janssens, \\ Frank E Rademakers and Jan Bogaert
}

Address: Gasthuisberg University Hospital, Leuven, Belgium

* Corresponding author

from I th Annual SCMR Scientific Sessions

Los Angeles, CA, USA. I-3 February 2008

Published: 22 October 2008

Journal of Cardiovascular Magnetic Resonance 2008, I0(Suppl I):AI5I doi:I0.|I86/I532-429X-I0-SI-AI5 I

This abstract is available from: http://jcmr-online.com/content/I0/SI/AI5I

(C) 2008 Masci et al; licensee BioMed Central Ltd.

\section{Background and purpose}

We sought to evaluate the influence of infarct size on infarct healing and left ventricular (LV) remodeling in patients with a first, successfully reperfused ST-elevation myocardial infarction (STEMI) using MRI.

\section{Methods and results}

Fifty-eight patients were studied in the first week $(1 \mathrm{~W})$ and 4 months $(4 \mathrm{M})$ after the acute event. At $1 \mathrm{~W}$, infarct size was related to infarct transmurality $(\mathrm{r}=0.62, \mathrm{p}<$ $0.001)$, infarct surface $(r=0.78, p<0.001)$, circumferential and longitudinal infarct length $(\mathrm{r}=0.67, \mathrm{p}<0.001$ and $r=0.69, p<0.001$, respectively), concomitant microvascular obstruction $(\mathrm{r}=0.74, \mathrm{p}<0.001)$, area at risk $(\mathrm{r}=$ $0.78, \mathrm{p}<0.001)$ as well as the ratio of infarct size to area at risk $(\mathrm{r}=0.68, \mathrm{p}<0.001)$, and inversely related to systolic wall thickening in the infarct $(\mathrm{r}=0.45, \mathrm{p}<0.001)$ and peri-infarct area $(r=0.37, p=0.004)$, and LV EF $(r=0.59$, $\mathrm{p}<0.001$ ). The median of normalized infarct size at $1 \mathrm{~W}$, ie, $17.1 \%$ of LV mass, was used to create a small and large size infarct group. Large infarcts presented with higher maximum serum troponin I levels than small infarcts $(115 \pm 68 \mu \mathrm{g} / \mathrm{L}$ versus $60 \pm 28 \mu \mathrm{g} / \mathrm{L}, \mathrm{p}=0.003$. While shrinkage in infarct size at $4 \mathrm{M}$ was similar between groups ( $43 \pm 18 \%$ in small versus $42 \pm 16 \%$ in large infarcts, $\mathrm{p}=0.99)$, the infarct surface did shrink significantly more in small $(15.7 \pm 15.9 \%)$ than large infarcts $(4.0 \pm$ $11.9 \%), \mathrm{p}=0.005$ with most pronounced differences in longitudinal direction, i.e. $14.5 \pm 12.5 \%$ in small versus
$5.0 \pm 8.6 \%$ in large infarcts, $p=0.003$. On the other hand, thinning of the infarcted wall was more pronounced in large $(29.8 \pm 18.8 \%)$ than in small infarcts $(13.5 \pm 22 \%)$, $\mathrm{p}=0.004$. Functionally, small infarcts recovered systolic wall thickening in the infarct $(p=0.01)$ and peri-infarct area $(\mathrm{p}=0.004)$, matching with improvement in LV EF $(52.7 \pm 7.0 \%$ at $1 \mathrm{~W}$ tot $55.7 \pm 7.3 \%$ at $4 \mathrm{M}, \mathrm{p}=0.003)$, while large infarcts showed a lack of recovery in regional or global LV function. At $1 \mathrm{~W}$, large infarcts showed more pronounced flattening of the infarcted myocardium as expressed by a larger circumferential radius of curvature ( $\mathrm{p}$ $=0.019$ ). At $4 \mathrm{M}$ infarct size was related to expansion of the remote myocardium (circumferential radius of curvature at end diastole: $\mathrm{r}=0.45, \mathrm{p}=0.001$, end systole: $\mathrm{r}=$ $0.54, \mathrm{p}=0.001$ ), and global adverse remodeling (LV EDV $\mathrm{r}=0.39, \mathrm{p}=0.003 ;$ LV ESV $\mathrm{r}=0.58, \mathrm{p}<0.001, \mathrm{LV}$ EF $\mathrm{r}=$ $0.61, \mathrm{p}<0.001)$.

\section{Conclusion}

The amount of necrotic myocardium strongly determines the pattern of infarct healing, and regional and global LV remodeling. Small infarcts show favorable infarct healing (less thinning, more surface shrinkage) and remodeling with a beneficial impact on regional and global function. Large infarcts, in contrast, show more extensive infarct thinning, lack of infarct surface shrinkage leading to adverse remodeling, and lack of functional recovery. 